\title{
PEDAGOGIA DA VIDA: POR UMA EDUCAÇÃO EM SAÚDE DESDE SI MESMO
}

PEDAGOGY OF LIFE: FOR HEALTH EDUCATION STARTING WITH ONESELF

\section{PEDAGOGÍA DE VIDA: POR UNA EDUCACIÓN PARA LA SALUD QUE COMIENZA EN SÍ MISMO}

\begin{abstract}
Alexandre Franca Barreto *
\section{Resumo}

Este trabalho tem por objetivo refletir sobre uma educação integral em saúde intitulada Pedagogia da Vida. O pensamento reichiano serve de base e alinha-se a uma perspectiva vitalista de afirmação e busca de Vida potente em contínua fluição. Nesta pedagogia apontamos três intencionalidades do educador: a construção de vínculo seguro; o trabalho corporal reichiano e loweniano (pós reichiano), e; um espaço protegido de integração das experiências. Em seguida, apresentamos a metodologia de pesquisa testemunhal que nos favorece penetrar na experiência do educando. O testemunho serve como dado para reflexão de uma pedagogia que parte do corpo e busca desenvolver um saber profundo, atento a fluição da Vida em si mesmo. Esta atitude auxilia a integrar mente e corpo, a vida íntima/pessoal, trazendo potencia a Vida do educando de modo amplo.
\end{abstract}

Palavras-chave: pensamento reichiano, corpo, testemunho, Vida, educação em saúde.

\begin{abstract}
This paper sets out reflections on health education based on Reich which we call Pedagogy of Life. The hallmarks of Reich's thought within the educational field are New School and a historical-critical approach. Marxism, Freudianism and Bergsonism serve as philosophical influences. The singularity of this aspect of education is study of the body. Our starting point
\end{abstract}

\footnotetext{
* É psicólogo graduado pela Universidade Católica de Pernambuco, Especialista em Psicologia Clínica - ênfase em Análise Bioenergética no Libertas (PE), mestre em Antropologia pela Universidade Federal de Pernambuco e doutor em Educação pela Universidade Federal de Pernambuco (2013 2016). Há oito anos vive no sertão nordestino, em Petrolina (PE), onde trabalha como docente na Universidade Federal do Vale do São Francisco (UNIVASF), ministrando aulas no curso de Psicologia e na Residência Multiprofissional em Saúde da Família (UNIVASF/SESAB).
} 
is to have education for Life as it is Lived which diverges from a hegemonic model of anti-life education. Then we present the methodology of testimonial research which benefits us since by this means we can probe into the student's experience of how we operate the Pedagogy of Life. Therefore, we take a student's testimony as an item of data for reflecting on a pedagogy that comes from the body and seeks to develop profound knowledge starting with the student himself/herself.

Keywords: Reichian thought, body, testimony, Life, Health Education

\section{Resumen}

Este trabajo tiene como objetivo reflexionar sobre una educación reichiana para la salud que han titulado la pedagogía de la Vida. El pensamiento del Reich en el campo de la educación trae influencias de la Escuela Nueva y enfoques histórico-críticos. El marxismo, el freudismo y bergsonismo son influencias filosóficas. El aspecto único de este tipo de educación es el trabajo corporal. Dejamos la educación para VivaVivaz que diverge de un modelo hegemónico de educación contra la vida. A continuación se presenta la metodología testimonio que favorece a penetrar en la experiencia del estudiante acerca de cómo operamos la pedagogía de la vida. Por lo tanto, el testimonio de un estudiante sirve de datos para la reflexión de una pedagogía que parte del cuerpo y tiene por objeto desarrollar un conocimiento profundo de sí mismo.

Palabras clave: pensamiento de Reich, cuerpo, testimonio, la vida, la educación para la salud.

\section{Da pedagogia da Vida}

A pedagogia da Vida $^{1}$ fundamenta-se em pressupostos teóricos reichianos tendo como central a noção de Vida. Para Reich a Vida é um contínuo fluir em seu movimento natural um ininterrupto movimento de expansão e contração. Esta fluição é a expressão básica da energia vital, que existe em um protoplasma, nas primeiras formas de vidas na Terra e em nossa constituição celular embrionária ${ }^{2,3}$.

Este princípio de funcionamento comum (contínuo fluir de expansão e contração) da Vida mostra-se também em nossos movimentos corporais vitais a exemplo do funcionamento cardíaco, da respiração e do peristaltismo intestinal. É igualmente o movimento da vida em 
nosso planeta (a exemplo das estações do ano, do nascimento e morte), que por sua vez segue o mesmo princípio de funcionamento do universo. Podemos perceber na atmosfera e nos movimentos dos corpos celestes (como o sol e a lua) este contínuo movimento de expansão e contração ${ }^{2,4,5}$. Esta visão reichiana, como ele próprio nos diz, procura "enquadrar a vida humana infinitamente pequena e sua vida social na órbita infinitamente grande do processo natural geral; procura eliminar o conflito criado por um "desenvolvimento errôneo" da natureza" (Reich ${ }^{6}$, p. 30).

Aqui o que está em foco não é simplesmente uma crítica da cultura que distancia o homem de si mesmo tendo como alternativa um retorno à natureza primitiva, tal como presente na clássica tese rousseauniana do bom selvagem. O pensamento reichiano, ao nosso ver, fortemente influenciado pela psicanálise, marxismo, antropologia, biologia e física, traz uma concepção muito própria que antecipa discussões presentes em abordagens sistêmicas e na filosofia pós estruturalista acerca da Vida humana ${ }^{7,8}$.

Vale salientar que esta visão de Reich, apesar de muito própria, não foi construída de modo isolado ou descontextualizado de sua prática clínica, da militância política, dos trabalhos de caráter educativo e de estudos laboratoriais, fazia parte, em maior ou menor medida, de uma força contra hegemônica que coexistia no meio acadêmico e científico de sua época. Uma de suas leituras prediletas durante sua formação médica era Bergson, considerado por alguns leitores de Reich como sua principal influência filosófica ${ }^{9}$. Vemos, então, sua aproximação à noção de vida bergsoniana. Para o filósofo "[...] o ser vivo é sobretudo um lugar de passagem, e que o essencial da vida está no movimento que a transmite" ${ }^{10}$ (p.124). Aqui fica evidente a centralidade na fluição como aspecto determinante da vida para ambos.

Para Reich esta fluição segue um contínuo movimento de contração e expansão como já foi dito. Já Bergson toma outra expressão para designar o movimento da vida:

"A vida é tendência e a essência de uma tendência é desenvolver-se em forma de feixe, criando, pelo simples fato de seu crescimento, direções divergentes entre as quais seu elã irá dividir-se"10 (p.97). O que há em ambos os pensadores é a noção de movimento divergente da vida- seja nas extremidades opostas de um feixe, seja na oposição presente nos movimentos de contrair e expandir.

Bergson ainda nos diz que: “A vida em geral é a própria mobilidade, as manifestações particulares da vida só aceitam esta mobilidade a contragosto e estão constantemente atrasadas em relação a ela." (Bergson ${ }^{10}$, p.123). Reich ${ }^{4}$, compreendendo de forma similar, acreditou que esta divergência fundamental da vida se expressa na existência humana, muitas vezes a contragosto. Para ele nossa cultura dominante tende a estagnação como um 
movimento de defesa ao imponderável. A couraça presente nos corpos humanos em nossa sociedade é uma expressão resultante deste conflito. Ao longo de seu trabalho e vida Reich percebeu que a doxa cultural tergiversava a família, a religião, a ciência, a política e a economia em diversas instituições sociais, e revelavam-se como lócus original e prioritário de seu trabalho clínico e científico no próprio corpo e relação humana.

Os estudos de Jonhson ${ }^{11,12}$ que tomam por base o pensamento reichiano são particularmente significantes neste aspecto, a medida que o autor aprofunda sua reflexão desta paradoxal noção de corpo como cenário principal das lutas de transformação simultaneamente íntimas e sociais. Quanto mais nos aprofundamos no corpo, adentramos paradoxalmente na singularidade e na totalidade - uma trama de indissociabilidade dos processos corporais, sociais e espirituais da Vida. O autor adota seu próprio testemunho ${ }^{12}$ bem como toma a biografia de Gandhi ${ }^{11}$, como um exemplo de ativista político e espiritual que tinha em seu corpo as principais lutas para libertação de sua nação e a busca profunda pela verdade. Neste aspecto, o autor relata que simples ações cotidianas, práticas corporais orientais, associadas às curas com água e terra, jejum, alimentação vegetariana e fitoterapia eram recursos ativos da luta contra o colonialismo inglês. Johnson nos diz a respeito de Gandhi: "Sua atenção rigorosa [ao corpo] teve o propósito de fortalecer o revolucionário para os grandes desafios de resistência à violência" (Johnson ${ }^{11}$, p. 36). Em seguida afirma que a impossibilidade de viver a liberdade em nossa sociedade está enraizada no corpo humano ${ }^{11}$.

Seguindo esta visão indissociável de corpo e vida potente, Lowen, autor do campo pós-reichiano, constrói uma visão de self corpóreo - enquanto consciência do próprio corpo si mesmo ${ }^{13,14}$. O autor afirma que "não se pode encontrar segurança em nenhum processo racional dissociado de suas raízes nos sentimentos do corpo" ${ }^{14}$ (p.207).

Aqui pontuamos a principal divergência reichiana com o bergsonismo: a materialidade da energia vital expressa no próprio corpo. Para Reich há uma cisão operada por Bergson entre domínios metafísico e físico. Esta cisão se mostra visível na concepção de uma energia da Vida de caráter metafísico (o elán vital bergsoniano), em contraposição a sua energia orgone que poderia ser comprovada fisicamente e trabalhada corporalmente através de técnicas de respiração, movimentos corporais expressivos, massagens em regiões específicas além de outras possibilidades de manu seio desta energia em prol da vitalidade do sujeito ${ }^{2,5}$.

Ao enfatizarmos a Vida estamos dando ênfase a noção de Vida Viva, é uma orientação ideativa reichiana, da possibilidade de uma plena existência ancorada na integração do homem em suas funções vitais, sem contradizer natureza e cultura, mas operando de modo integro em uma troca cósmica de profundo amor, sabedoria e dedicação com todos os seres e 
coisas. Mas a Vida Viva não é uma Vida mistificada, no sentido de negar a carne, pois é justamente no mergulho profundo das sensações e emoções corporais que encontraremos esta chama que nutre a Vida Viva, sendo a própria experiência sexual uma das formas mais profundas de conectar-se com a essência desta. Contudo, a Vida Viva não se reduz exclusivamente a materialidade, não é uma experiência mecânica, mas animada pelo espírito, o qual traduz-se pela energia cósmica (orgônio) em sua forma autoconsciente que procura desenvolver-se rumo a plenitude de sua realização, em uma tendência inata ao crescimento, enraizada na natureza ${ }^{2,4}$.

Esta noção de Vida não tem a intenção de idealizar o sujeito, mas de traçar um horizonte para um caminho de si mesmo. Para Reich o prazer e alegria da vida são inconcebíveis sem luta, sem experiências dolorosas e desagradáveis auto-avaliações. A própria noção de uma saúde psíquica é caraterizada por ele como "um movimento de alternância entre a luta desagradável e a felicidade, entre o erro e a verdade, entre a derivação e a volta ao rumo, entre o ódio racional e o amor racional; em suma, pelo fato de se estar plenamente vivo em todas as situações da vida" $\left(\right.$ Reich $^{5}$, p. 175).

Deste modo, o que temos é uma perspectiva reichiana vitalista que como é acentuada por Ávila ${ }^{15}$ trata-se de um vitalismo caraterizado como uma atenção permanente ao que vem; aos modos de viver, mas especificamente, as formas em que a Vida se quer a si mesma. Deste modo, temos uma aproximação do pensamento reichiano à ontologia vitalista deleuziana. Nossa modo de entender a perspectiva reichiana se aproxima tanto da possibilidade de deleuziana de adotar conceitos em novas coordenadas histórias e com isto trazer uma leitura reichiana e perspectiva vitalista atualizada as questões contemporâneas. Bem como se vincular a uma noção vitalista de liberar a vida daquilo que a aprisiona e diminui sua potência. Em busca de um.pensamento que vá ao limite do que pode a vida - de afirmação da Vida, em lugar de um conhecimento que se opõe a fluição e potencia da vida ${ }^{16,17,18}$.

Os laços do pensamento reichiano com uma educação para a afirmação da Vida são visíveis em seus escritos ${ }^{19,20}$. O celebre educador inglês A.S. Neil adotou conceitos reichianos para fundamentar a prática pedagógica libertária da Escola de Sumerhill no século passado. Aqui no Brasil podemos ver diversos estudos que trazem à tona diversas contribuição do pensamento reichiano no campo educacional ${ }^{19,20,21,22}$.

Esta pedagogia da Vida não se atém às exigências acadêmicas e profissionais do mercado de trabalho, ou da própria normativa da cidadania crítica do ensino universitário, pois trata da Vida Viva, é formação humana. É um apelo contra a acentuada fragmentação do conhecimento, a tecnificação dos procedimentos profissionais, o desperdício da experiência - 
da intensidade de sensações e dos sentidos que validam singularidade da Vida -, a flagelação da Vida e da miséria social - contra o desvio básico da Vida - que para Reich era o encouraçamento, o enrijecimento que tendia a estagnação, limitando a fluição natural da Vida. Esta pedagogia busca o humano em uma singularidade que desenraizado da natureza (vida em potencia) por um estreitamento acentuado do horizonte da educação, necessita de religar-se de modo mais profundo e íntegro com si mesmo. Busca-se caminhos de "fuga" da prisão, ou, melhor dizendo, o enraizamento na natureza humana de pura fluição, através de caminhos de reconciliação com a Vida ${ }^{1}$.

Por centrar-se na própria Vida em si mesmo não descrevemos procedimentos rígidos de trabalho, no entanto sinalizamos três intencionalidades do educador que contribuem para que a Vida possa fluir nas relações educativas e na própria realidade da existência. 1) A construção de vínculo seguro - que permite a relação educativa fluir com liberdade e profundidade; 2) O trabalho corporal reichiano e loweniano (pós reichiano) como recurso de acesso a experiência profunda de si mesmo, e; 3) Espaço protegido de partilha e integração das experiências que permite a intensidade da experiência seja elaborada, produzindo sentidos e potencia para a própria Vida em sua fluição ${ }^{1}$.

\section{O testemunho como método de Pesquisa}

É no século XX que o testemunho vem ocupando um significativo valor, "elementar" (para tomar de empréstimo o termo adotado por Seligmann-Silva) para narrar a experiência humana em situações traumáticas e de catástrofes (Seligmann-Silva ${ }^{23,24,25}$ ) como o fez Primo Levi $^{26}$ acerca de sua experiência no campo de concentração nazista (Agamben ${ }^{27}$ ).

Porém, o testemunho nos serve para evidenciar não apenas a resistência à violência da guerra e da intolerância humana, mas como aponta Pierron ${ }^{28}$, também serve para atestar a "resistência nestes tempos de paz em que o sistema técnico se impõe como um novo destino em escala mundializada" ${ }^{28}$ (p.257).

Nas palavras de Pierron ${ }^{28}$, o testemunho é um modo de "certificação existencial" quando o vivido já não permite que nos refugiemos "sob um estatuto profissional, relacional ou mesmo confessional, que lhe garantiria uma identidade imutável e definitivamente estabelecida" ${ }^{28}$ (p.12).

No campo da educação, o testemunho foi utilizado por Georges Gusdorf em sua obra "Professores para quê? Para uma pedagogia da pedagogia". Neste trabalho Gusdorf ${ }^{29}$ procura resgatar que considera de fundamental na educação - a singular relação dialógica de mestre- 
discípulo. Ele nos diz que "o meio direto é solicitar o testemunho" daqueles que despertam "pelo acaso de um encontro, para uma nova e mais autêntica consciência de si mesma". ${ }^{29}$ ( p. 73).

Neste sentido, esta pesquisa não quer evidenciar um evento catastrófico nos termos de literatura de Shoah. Mas, ao destacar eventos da "normalidade catastrófica" da vida dos educandos, o espaço da universidade transforma-se em um território de transformação de si mesmo no qual a fluição da Vida leva tais educandos a caminhos (in)desejáveis de potencia. Tornamos sensíveis para perceber no encontro com o outro, desde si mesmo, o sofrimento (com maior ou menor intensidade) da "normalidade" do corpo encouraçado, lócus de vida estagnada. Nossa ênfase é na resistência humana, é na fluição que irrompe da relação educativa e que faz contraponto diante da hipervalorização da formação técnica. $O$ testemunho é assertivo, mesmo com sua aporia, narra nos limites do inarrável, o estridente e silencioso martírio face aos processos produtivistas e utilitaristas de atravessam as instituições educadoras dede nosso tempo. Esta posição justifica-se por estarmos vivendo dentro de um sistema educacional que acentua as dimensões que contribuem para a tecnificação da formação, desqualificando, muitas vezes, o valor da experiência humana em sua integralidade por um estreitamento e empobrecimento da formação humana e do horizonte da educação no contexto universitário.

O iremos focar no testemunho que se segue é o movimento de uma existência. Mas particularmente a transmissão desta pedagogia na, Vida que se revela com suas dispersões e contradições em um contínuo processo de fluir desde si mesmo, ainda que se des-construa, refaça e (in)deseje, vemos uma potencia, e, talvez mesmo uma "coerência" na ambiguidade que marca a própria Vida em fluição.

Nossa análise neste modo, baseia-se nesta dimensão de transmissão do testemunhosinalizada por Pierron ${ }^{28}$. A transmissão testemunhal procura fazer entender as questões que contam enquanto questões vivas, destacando a interrogação e a intuição que faz depender o acesso à verdade de um trabalho formativo sobre si mesmo. Nesta direção, no próprio pensamento freireano é possível localizar um acento na transmissão testemunhal, quando o autor destaca a necessidade do educador corporificar as palavras pelo exemplo: "não há pensar certo fora de uma prática testemunhal que re-diz em lugar de desdizê-lo"30 (p. 34).

Deste modo, o que analisamos no testemunho a seguir é o que foi transmitido nesta relação pedagógica, o que conta, na Vida da testemunha, desta experiência educativa. Iremos destacar as três intenções de nossa pedagogia (o vínculo seguro o trabalho corporal e a integração da experiência) e o que elas produziram na Vida do educando. 
O testemunho foi feito por um educando que pode vivenciar o trabalho baseado em nossa pedagogia da Vida. Como sinalizado pela testemunha, tivemos dois encontros durante sua graduação em atividades curriculares. O convite para escrever um testemunho textual foi feito por um dos pesquisadores e foi coletado cerca de três anos depois da última atividade relatada em seu texto Esta comunicação entre pesquisador e testemunha foi através de rede social e correio eletrônico. Por se caracterizar em uma pesquisa que emergiu espontânea e contingencialmente na prática profissional docente e que buscamos preservar o anonimato do educando tanto omitindo seu nome, o curso de graduação em saúde que realizou, como também alterando algumas informações referentes a período/contexto que estudou tais disciplinas. Por estes motivos, baseados na Resolução no 510, de 07 de abril de 2016 do CNS (Conselho Nacional de Saúde) não foi necessária a submissão ao Comitê de Ética em pesquisa.

\section{Testemunhando o cuidado de si mesmo na formação em saúde}

Passemos ao testemunho do educando que nos ajuda a compreender o modo como nossa pedagogia esforça-se para trazer potencia a Vida integrando a vida íntima/pessoal e profissional. Mauro (nome fictício) testemunha como a experiência educativa o ensina no cuidado de si mesmo. Abaixo segue seu texto enviado com o objetivo de colaborar com este estudo.

Decidi cursar uma das disciplinas optativas que estavam sendo ofertadas. A disciplina era tanatologia e achei interessante, além de importante, discutir um pouco sobre o processo do morrer em nossa sociedade. Sabia que lidaria com a situação da morte diversas vezes em minha vida profissional e era necessário começar a vivenciar aquilo tudo. Não sabia, mas haveria ali algo que me encantaria: a bioenergética ${ }^{\dagger}$. Foi apenas um encontro durante toda a disciplina, mas foi mais marcante do que eu imaginava. Para começar eu não fazia ideia do que se tratava, nunca tinha ouvido falar de bioenergética e não sabia o quanto aqueles encontros mudariam minha vida.

$\mathrm{O}$ encontro se iniciou de maneira calma, eu testemunharia uma mulher, adulta e mãe voltar aos braços de alguém chorando em posição fetal por recordar historias de seu passado. Não sei descrever o que senti naquele momento, mas com certeza foi algo entremeado pelo encantamento, pelo espanto e pelo medo. $\mathrm{O}$ fato é que naquele mesmo dia, terminei a noite ao lado de um grande amigo (que sempre teve enorme dificuldade de lidar com seus sentimentos) sentados à mesa de um bar, vendo aquele homem chorar na minha frente e tomar decisões que foram fundamentais em sua vida.

Algum tempo depois iniciei uma outra disciplina que abordaria as Práticas Integrativas e Complementares (PIC). Optei por me adentrar um pouco mais

\footnotetext{
† Bioenergética ou Análise Bioenergética é a denominação de uma abordagem de Psicologia Somática desenvolvida pelo médico M.D. Alexander Lowen, em um enfoque neo-reichiano.
} 
no mundo da bioenergética. Eram os momentos onde o peso que eu carregava durante toda a semana seria descarregado.

E quão bem aqueles momentos me fizeram. Ali ao lado de várias colegas vi histórias do passado serem recontadas, aflições sendo revividas, momentos de felicidade sendo recontados. Vi pessoas se reencontrando consigo próprias. Mas algo em mim ainda precisava ser vivido. Ao fim de tudo contribuímos com um trabalho belíssimo que estava sendo realizado com senhoras hipertensas no serviço público de saúde. Foi lindo ver como aquelas mulheres se entregaram à proposta que levávamos. Como tecnologias tão leves eram capazes de trazer tanta transformação para a saúde das pessoas.

Entretanto, o momento mais marcante de todos esses espaços e que jamais esquecerei aconteceu em um de nossos encontros. Até esse dia, todos os exercícios, posições e groundings* (confesso não me recordar de todos os nomes com clareza... rsrs) conseguiam me relaxar, me deixar mais leve, me fazer rir e me deixar mais feliz. Nenhum dos momentos ainda havia ativado dentro de mim algo maior ou mais complexo. Sempre via as outras meninas chorando, vivenciando algo aparentemente mágico e especial, mas comigo isso não acontecia. Naquela noite foi diferente. As posições trabalhadas naquela noite buscavam trabalhar com nossa sexualidade, e foi em uma dessas posições que aconteceu. Lá estava eu deitado, braços estendidos ao lado do corpo, pelve elevada, quando o tremor característico de todas as aulas começou a tomar conta de mim, mas daquela vez de forma muitíssimo mais intensa. Meu corpo todo tremia e de repente lágrimas começaram a querer cair dos meus olhos. Eu não sabia o motivo, eu (ao menos conscientemente) não estava pensando em nada, mas a vontade era cair desesperadamente no choro. Foi quando o professor perguntou se eu queria interromper e descansar um pouco ou queria continuar. Fiquei tão assustado no momento que optei por parar sem sequer pensar no que estava acontecendo. Passei o restante do encontro calado e só algum tempo depois consegui compreender o quanto a questão da sexualidade me atingia. Sou gay e naquela época ainda estava enfiado dentro do armário, sem compreender que haveria possibilidade de felicidade aceitando minha orientação. E, só depois que me aceitei, percebi o quanto me tornei extremamente mais feliz, o quanto um nó foi desfeito em minha vida e o quão mais fácil se tornou simplesmente "viver". O fato é que aqueles momentos foram de fundamental importância para mim. Tanto pessoal quanto profissionalmente.

Podemos ver no testemunho de Mauro a importância de nossa relação pedagógica em sua Vida. Encantamento, espanto, medo, descarga de pesos, leveza, relaxamento, tremores, tristeza, choro, felicidade e riso são algumas das sensações e sentimentos relatados por ele. Viver tais sensações e emoções de modo consciente, percebendo-os no próprio corpo, podendo expressá-lo e reconhecendo os motivos de emergência delas é o que substancialmente nos leva a uma formação de si mesmo conduzida pela fluição da vida que há

\footnotetext{
¥ O grounding (enraizamento) é um conceito central na teoria loweniana. É compreendido igualmente como uma postura corporal (estar com os pés no chão, em contato com a terra, apoiado em suas próprias pernas e pés) e uma disposição diante de si e do mundo (estar em contato e conectado com a realidade de si mesmo e do mundo).
} 
no próprio corpo (si mesmo). Esta nos parece ser a base transmissional de nossa pedagogia o acesso a si mesmo.

Entretanto, para que este acesso possa ocorrer temos uma estruturação de um vínculo seguro que suportará toda esta intensidade de Vida emotiva e sensitiva expressa pela verdade do corpo, no qual as potencias pedagógicas se permitam expressar dando a coragem necessária para olhar e reconhecer o próprio medo de si mesmo. Neste ambiente educativo, que presa pela ausência de julgamentos e por uma fala pessoal (a partir de si mesmo), os processos educativos podem ocorrer com fluidez uma mulher, adulta e mãe pode voltar aos braços de alguém chorando em posição fetal, as pessoas podem reconectar-se com experiências do passado, podem expressar emoções e sensações que outrora foram contidas ou reprimidas por não se sentirem em ambiente seguro e acolhedor.

O trabalho corporal é uma segunda intencionalidade transmitida. No testemunho é visível quando se relata os exercícios, posturas, posições $e$ "groundigs" realizados. Lowen e Lowen ${ }^{31}$ comenta: "grounding representa o contato de uma pessoa com as realidades básicas de sua existência" (p. 23). Estar em grounding, essencialmente falando, é estar conectado com si próprio e o mundo de modo íntegro, trabalhando as cisões e a sobrecarga da vida em si mesmo. Por mais simples e óbvio que este conceito de grounding possa parecer, o que Lowen nos diz, assim como constatamos em nossa experiência de trabalho, é que é muito comum as pessoas estarem desconectadas de seus corpos apesar de existirem neles, bem como do próprio chão que pisam e que dá sustentação para toda vida humana. Por este motivo os exercícios tem a finalidade de estimular a conexão com si mesmo. Este trabalho não é feito mecanicamente, nem de forma estereotipada, é simplesmente, um convite de movimentar o corpo com cuidado e respeito por si mesmo, deixando que a fluição da Vida no corpo nos conduza. As expressões emocionais irrompem espontaneamente ao longo do trabalho são acolhidas. O exercício apresenta uma dimensão expressiva e tem uma compreensão atualizada da noção de catarse com base nos efeitos evidenciados no campo das neurociências que pontuam dois benefícios: uma que trata do efeito de purificação e outra que evidencia a causa e o processo de tal purificação.

Juntas, elas [as duas ênfases] levam em conta a emergência dramática na consciência (insight): o processo que traz algo do início/de dentro (transtorno emocional) até o final/para fora/ para a superfície (expressão). Também, levam em conta a mudança nas cargas quantitativa e qualitativa (liberação da tensão e renovação espiritual). Assim, a catarse é um conceito que envolve vários processos distintos e diferentes ${ }^{32}$ (p. 232). 
Deste modo, nosso trabalho evita o risco de uma educação acentuadamente intelectual que dissocia o exercício mental das sensações e emoções do corpo. Tal como Reich ${ }^{33}$ já sinalizava "a atividade intelectual pode ser estruturada e dirigida de maneira a parecer um hábil aparelho, cujo fim é precisamente evitar a cognição, isto é, assemelha-se a uma atividade que nos afasta da realidade" ${ }^{, 33}$ (p. 285).

Reich $^{33}$ já ressaltava que a função intelectual é uma atividade vegetativa (viva de movimento fluído) e tem uma carga de afeto vivo similar a um impulso dito meramente afetivo.

Um exercício intelectual objetivista dissociado do afetivo necessita justamente de uma disciplina corporal dolorosa, que bloqueia as sensações e emoções do corpo ao exigir poucos movimentos nos ambientes de sala aula, encurtar a respiração e desqualificar qualquer expressão emocional ou sensação mais intensa. Subordina igualmente o pensamento criativo a uma atividade mecanizada e repetitiva, de modo que a Vida seja apenas expressa em seu aprisionamento, e não em sua potencia de fluição. Lowen ${ }^{34}$ reforça esta afirmação:

Pensar objetivamente quando o corpo se encontra num estado de dor, ou não está tendo prazer, só é possível mediante o seu amortecimento, a fim de que se reduza a sensação dolorosa. Esse "amortecimento" dissocia a mente do físico fazendo com que a qualidade seja mecânica ou computadorizada. $\mathrm{O}$ pensamento criativo, que depende do fluxo livre de ideias conscientes, ocorre apenas quando o corpo está mais ativo e aliviado. Não podemos deixar de concluir que a qualidade do pensamento e, provavelmente, seu conteúdo, também não podem ser totalmente divorciados do tono emocional do $\operatorname{corpo}^{34}$ (p. 128).

Aprofundando ainda suas colocações, Lowen vai nos dizer que conhecimento e movimento são uma unidade e compreende que "o pensamento deriva do movimento" 34 (p.126), afirmando que "a maior capacidade de pensar do homem vem, em última instância, da maior extensão de movimentos de que ele é capaz" ${ }^{34}$ (p.126). Sob este aspecto, é inestimável o valor da expressividade e da mobilidade do corpo para o desenvolvimento de um pensamento íntegro e enraizado na realidade de si mesmo.

Com estes apontamentos chegamos ao terceiro aspecto da transmissão que podemos ver no testemunho, que se refere a integração das experiências. Quando Mauro se refere o trabalho educativo contribuiu tanto para sua vida pessoal como profissional - se tornou mais fácil simplesmente "viver". Entendemos que o educando afirma que ao trabalhar as dores inevitáveis da realidade da vida (incluindo o sofrimento diante da morte de familiares, das diferenças sexuais e de toda uma dimensão de violência que circunda a sociedade), quando 
reconhecidas, aceitas e cuidadas geram uma potencia de uma Vida que flui com maior liberdade. Neste sentido, formação profissional e pessoal estão integradas - estamos em um horizonte educacional mais amplo que trata da formação do humano. Nesta pedagogia integrar o humano e o profissional faz-se via a integração do corpo com a mente, da cabeça com o coração, das sensações, emoções e pensamentos.

Vivenciar em um ambiente de formação experiências de contato profundo consigo mesmo, bem como suportar e acolher tais experiências em grupo, ofertam um ensinamento necessário para desenvolver a capacidade de amparo humano diante de situações similares tão recorrentes no cotidiano do profissional de saúde. Entendemos que o profissional de saúde quando não desenvolve esta habilidade de escuta e reconhecimento de si mesmo fica limitado para ofertar amparo adequado às pessoas em sofrimento que demandam tal atenção.

Este conhecimento profundo que Mauro atinge acerca de sua Vida, e que o torna mais livre para ser si mesmo é, em certa medida, o mesmo que confere sensibilidade e sabedoria para escutar a experiência de sofrimento, bem como formular possibilidades de cuidado em seu exercício profissional.

\section{Considerações Finais}

O testemunho, como lembra Pierron ${ }^{28}$, aponta uma verdade "frágil" a mercê da suspeição e da contraprova. Frágil por ser inclusive uma ação pessoal, de um homem fragilizado e vulnerável em nosso mundo.

Entretanto, o testemunho tem seu valor na validação existencial da verdade, ou melhor dizendo, na validação de uma verdade com que se possa viver vivamente. Esta validação revela-se por vezes na Vida estranhamente mais certeira do que a argumentação racional de uma cultura dominada pela racionalidade tecnocientífica ${ }^{28}$.

Com isto dito, pensamos ter atingido o objetivo principal deste artigo que foi apontar para uma pedagogia da Vida que sinaliza uma concepção de educação integral em saúde de base reichiana ${ }^{1}$, que apesar de privilegiar a formação em saúde no contexto profissional e universitário brasileiro, amplia-se ideativamente para uma formação humana que se ocupa com a Vida na própria Vida que é tecida por laços e experiências educativas.

O maior impacto nas relações pedagógicas neste estilo é o de contribuir para uma formação de si mesmo, busca preservar e reparar a integridade humana na Vida, e, com isto, não dissociar uma formação profissional e científica, de uma formação humana, nem cindir o corpo da mente, a natureza da cultura. Igualmente revela a importância de escutar, cuidar e 
deixar-se ser guiado pelas sensações e emoções que brotam de forma espontânea de nosso corpo. Isto não significa uma abertura a qualquer tipo de expressão, mas sim uma abertura a Vida em sua potencia, na expressão e reconhecimento de si mesmo.

Aqui as três intencionalidades transmitidas (o vínculo seguro, o trabalho corporal e a integração das experiências) servem de guia para uma jornada de aprendizado e cuidado de si mesmo.

\section{Referencias Bibliográficas}

1. Barreto, A. F. Pedagogia da vida: um testemunho de formação humana. Porto Alegre, RS: Editora Fi, 2017.

2. Reich W.O Éter, Deus e o Diabo. 1a ed. São Paulo: Martins Fontes, 2003.

3. Keleman, S. S. Anatomia emocional: a estrutura da experiência. São Paulo: Summus, 1992.

4. Reich W. O Assassinato de Cristo. 5a ed. São Paulo: Martins Fontes,1999.

5. Reich W. A Função do Orgasmo. 19a ed. São Paulo: Brasiliense, 2004.

6. Reich W. A Revolução Sexual. 8a ed. Rio de Janeiro: Zahar Editores, 1982.

7. Boadella, D. Nos caminhos de Reich. 2a ed. São Paulo: Summus, 1985.

8. ALBERTINI, P. Na Psicanálise de Wilhelm Reich. São Paulo: Editora Zagodoni, 2016.

9.Albertini P. Reich: História das ideias e Formulações para a educação. 1a ed. São Paulo: Àgora, 1994.

10. Bergson, H. Memória e Vida: textos escolhidos por Gilles Delueze. São Paulo: Martins Fontes, 2006.

11. Johnson, D.H. Transformative Body Practices and Social Change: The Intersection between Spirituality and Activism. Integral Review. Volume 8, n01, p.35-42. Kings Mill: Ohio/USA, 2012.

12. Jonhson, D.H. Transpersonal Dimensions of Somatic Therapies. In: Hartelius, G., Friedman, H. (Org.). The Wiley - Blackwell Handbook for Transpersonal Psychology. USA: Wiley-Blackwell, 2013.

13. Lowen A. Narcisismo: negação do verdadeiro self. 9a ed.São Paulo: Cultrix, 1993.

14. Lowen, A. A espiritualidade do corpo: Bioenergética para a Beleza e a Harmonia. São Paulo: Summus, 1995.

15. Avila, D.C. Reich, Espinosa e a Educação. Dissertação de Mestrado. Programa de Pós Graduação em Psicologia da Universidade de São Paulo, 2010.

16. Deleuze, G. L’immanence: une vie. Philosophie, n. 47, p. 3-7, 1995. 
17. Landaeta, P.; Rojas B.; Cristi, A. M. Un vitalismo deleuziano: bosquejos sobre el diagrama Rev. Filos., Aurora, Curitiba, v. 29, n. 46, p. 73-94, jan./abr. 2017. Disponível em: http://dx.doi.org/10.7213/1980-5934.29.046.DS04

18. Canavera, J . El vitalismo de Gilles Deleuze . Daimon. Revista Internacional de Filosofía, no 66, 2015, 135-150. Disponível em: http://dx.doi.org/10.6018/daimon/194431

19. Sampaio Z. Educação e Liberdade em Wilhelm Reich. 1a ed. São Paulo: Perspectiva, 2007.

20. Matthiesen SQ. A educação em Wilhelm Reich: da psicanálise à pedagogia econômicosexual. 1a ed. São Paulo: UNESP, 2005.

21. Galves IC, Sass O. Wilhelm Reich e a Educação. PublICa (Natal). 2009; 5(1): 07 - 21.

22. Oliveira, IO. Prazer! Reich! A base de uma educação livre [dissertação]. Uberlândia (MG): Universidade Federal de Uberlândia; 2008.

23. Seligmann-Silva M, organizador. História, Memória, Literatura. O testemunho na Era das Catastrofes. 1a ed. Campinas: Editora da UNICAMP, 2003.

24. Seligmann-Silva M. Testemunhos e a Política da Memória: O tempo depois das catástrofes. Proj. História (São Paulo). 2005; (30): 71-98.

25. Seligmann-Silva M. Narrar o trauma: a questão dos testemunhos de catástrofes históricas. Psicol. clin. (Rio de Janeiro). 2008; 20(1): 65-82.

26. Levi P. É isto um homem? 1a ed. Rio de Janeiro: Rocco, 1988.

27. Agamben G. O que resta de Auschwitz: o arquivo e a testemunha (Homo Sacer III). 1a ed. São Paulo: Boitempo, 2008.

28. Pierron JP. Transmissão: Uma filosofia do testemunho. 1a ed. São Paulo: Edições Loyola, 2010.

29. Gusdorf G. Professores para quê? Para uma pedagogia da pedagogia. 3a ed. São Paulo: Martins Fontes, 2003.

30. Freire, P. Pedagogia da Autonomia. Saberes necessários à prática educativa. Rio de Janeiro: Paz e Terra, 1996.

31. Lowen A, Lowen L. Exercícios de Análise Bioenergética: Caminho para uma saúde vibrante. 8a ed. São Paulo: Ágora, 1985.

32. Reich W. Análise de Caráter. 3a ed. São Paulo: Martins Fontes, 2004.

33. Klopstech, A. Catarse e autorregulação revisitadas: considerações científicas e clínicas. Em: CLAUER, V.H. (Org.). Multiplos saberes em psicologia corporal: Análise Bioenergética (Volume 2). Recife: Libertas, 2015.

34. Lowen, A. Prazer: Uma Abordagem Criativa da Vida. 1a ed. São Paulo: Círculo do Livro, 1970 . 